\title{
РАЗРАБОТКА ТЕХНОЛОГИЧЕСКИХ РЕШЕНИЙ ДЛЯ ЗD-КАДАСТРА РОССИИ С УЧЕТОМ ПЕРЕДОВОГО ОПЫТА ЗАРУБЕЖНЫХ СТРАН
}

\author{
Александра Игоревна Иванова \\ Сибирский государственный университет геосистем и технологий, 630108, Россия, г. Новосибирск, \\ ул. Плахотного, 10, обучающийся, тел. (952)904-32-44, e-mail: ivanova-aleks.ivanova@yandex.ru
}

\section{Александр Викторович Чернов}

Сибирский государственный университет геосистем и технологий, 630108, Россия, г. Новосибирск, ул. Плахотного, 10, кандидат технических наук, доцент кафедры кадастра и территориального планирования, тел. (913)743-09-79, e-mail: avch-1011@mail.ru

В статье приведены результаты анализа передового зарубежного опыта в создании и внедрении 3D-кадастров недвижимости. Рассмотрена структура таких систем, базовые понятия и направления их развития. На основании полученных результатов, дана оценка возможности применения различных зарубежных технологических решений для внедрения в кадастр Российской Федерации.

Ключевые слова: 3D-модель, 3D-кадастр, объект недвижимости, модель

\section{DEVELOPMENT OF TECHNOLOGICAL SOLUTIONS FOR 3D CADASTRE OF RUSSIA, TAKING INTO ACCOUNT THE BEST EXPERIENCE OF FOREIGN COUNTRIES}

\section{Alexandra I. Ivanova}

Siberian State University of Geosystems and Technologies, 10, Plakhotnogo St., Novosibirsk, 630108, Russia, Ph. D. Student, phone: (952)904-32-44, e-mail: ivanova-aleks.ivanova@yandex.ru

\section{Aleksandr V. Chernov}

Siberian State University of Geosystems and Technologies, 10, Plakhotnogo St., Novosibirsk, 630108, Russia, Ph. D., Associate Professor, Department of Cadastre and Territorial Planning, phone: (913)743-09-79, e-mail: avch-1011@mail.ru

The article presents the results of the analysis of the best foreign experience in the creation and implementation of 3D real estate cadastres. The structure of such systems, basic concepts and directions of their development are considered. Based on the obtained results, an assessment of the possibility of using various foreign technological solutions for implementation in the cadastre of the Russian Federation was made.

Keywords: 3D-model, 3D-cadastre, real estate object, model

На данный момент архитектура объектов недвижимости имеет довольно разнообразный и сложный вид, что подразумевает под собой нахождение объекта и его частей не только на поверхности земельного участка, а также над или под ним. Это приводит к неопределенности и неоднозначности традиционной регистрации объектов по их двумерной проекции на земельный участок [1]. 
Земельные участки, здания, сооружения, помещения и объекты незавершенного строительства, невозможно точно отобразить в плоской проекции, что в дальнейшем делает практически невозможным осуществить учет некоторых объектов недвижимости [3], например, мостов, тоннелей, комплексов с нависающими этажами, проекции которых попадают на территорию смежных земельных участков. Сложившаяся ситуация указывает на потребность создания и внедрения систем 3D-кадастра. На рис. 1 приведен пример использования 3D-кадастра.

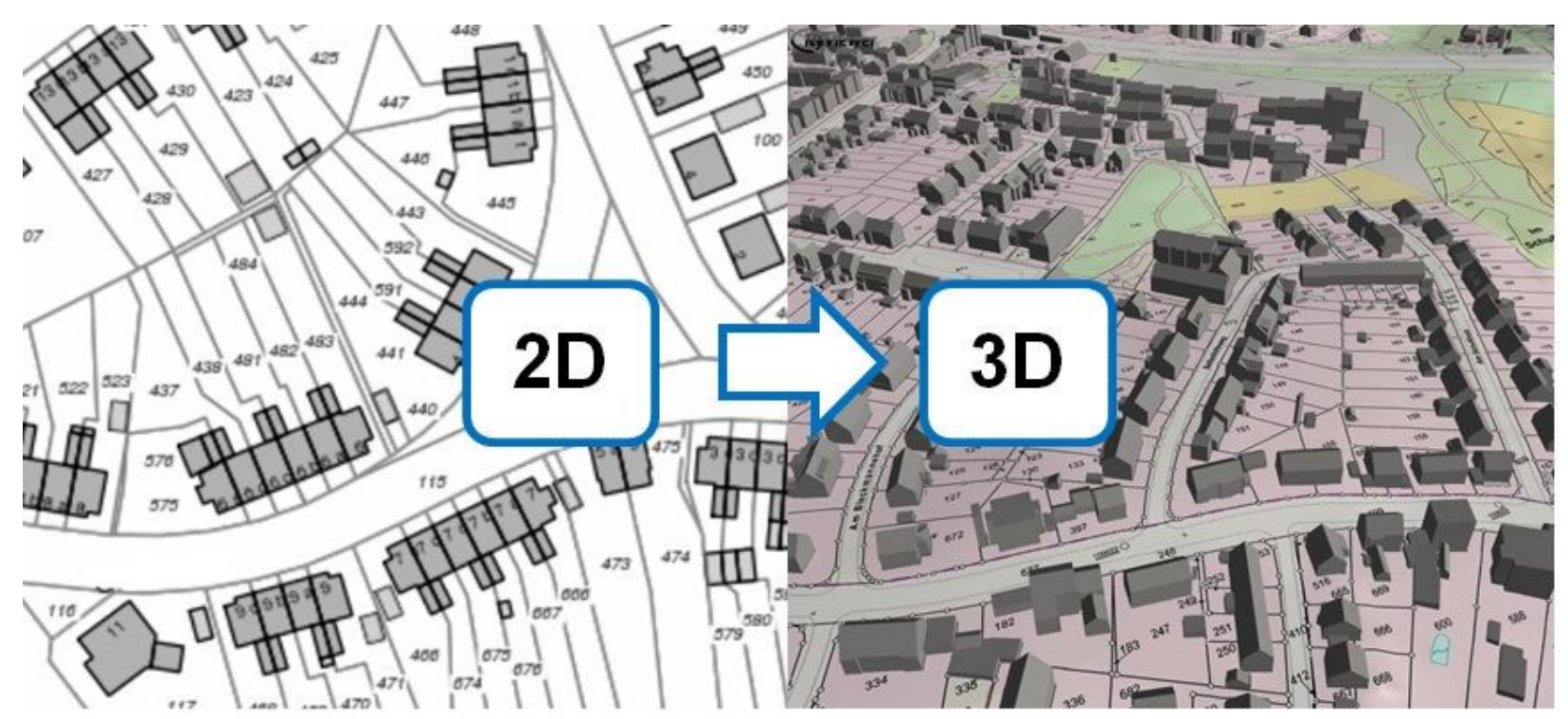

Рис. 1. 3D-моделирование в кадастре

В России в настоящее время существует система единого государственного реестра недвижимости, созданного на основе информационных технологий предоставления электронных услуг [2]. Такое решение позволяет гражданам быстро находить информацию об интересующих их объектах недвижимости, но только в 2D. Стоит отметить, что существует и ряд нормативно-правовых документов, регламентирующих понятие и содержание 3D-моделей объектов недвижимости, но их учет не ведется, в связи с недостаточным методическим обеспечением [5]. Исходя из этого, следует принимать во внимание наиболее успешные технологические решения зарубежных стран, которые могли бы значительно улучшить кадастровую систему России.

Целью данной работы является выполнение аналитического обзора передового опыта зарубежных стран для разработки технологических решений по реализации системы 3D-кадастра в России.

На основании изученного международного опыта, в рамках данной статьи были проанализированы кадастровые системы: Швеции, Китая и Нидерландов.

Швеция. В рассматриваемой стране введены особые изменения в законодательстве, основной причиной которых была реализация возможности регистрации прав на 3D-объекты. Таким образом, закон о формировании и учете 
3D-моделей объектов недвижимости был принят еще в 2004 году. Основной целью принятия данного нормативного акта являлось разделение прав собственности на магазины и на жилые помещения [9]. Такая же методика могла быть применена и для других объектов: мосты, туннели и т.д.

Следующим шагом стал ввод в 2019 году программы «Умная искусственная среда». Она предусматривает учет 3D-моделей объектов капитального строительства (ОКС) как фигур из вертикальных ребер, включающих пространство для учета выступающих конструктивных элементов объектов и его обслуживания, ограниченную горизонтальными гранями [7], соответствующую строительному проекту, пример на рис. 2.

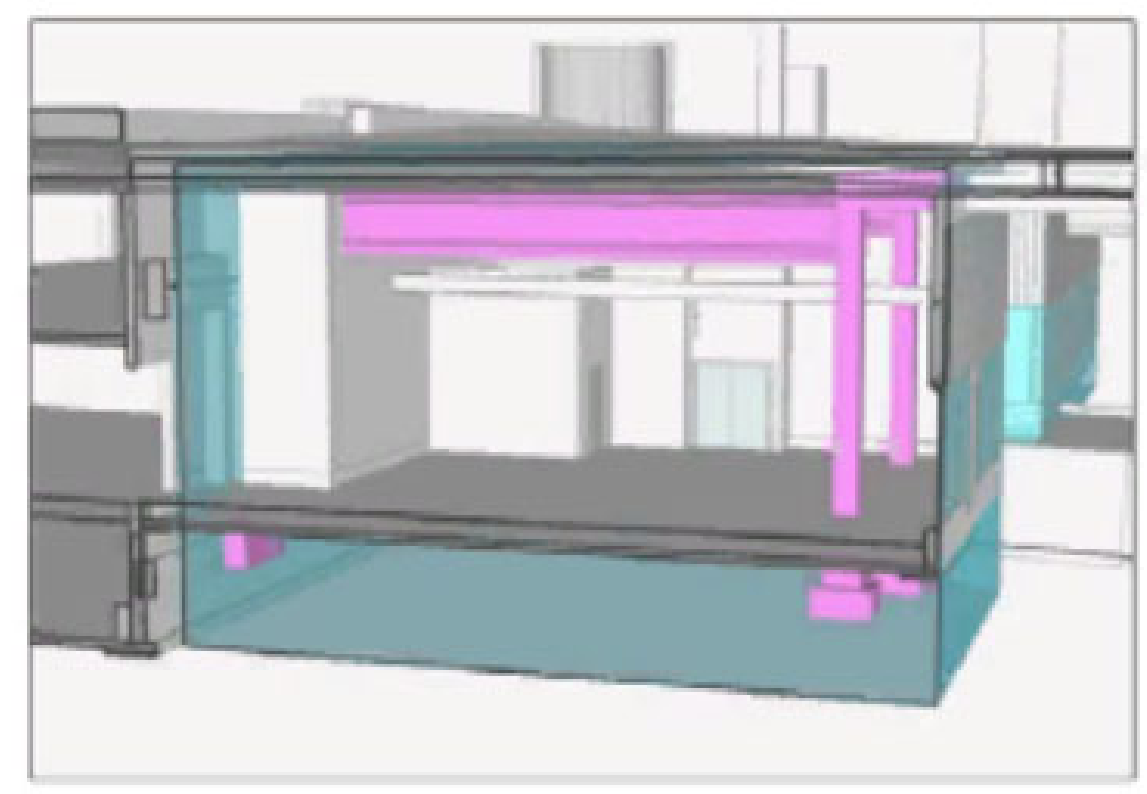

Рис. 2. Графическое представление 3D-моделей в Швеции

Для идентификации 3D-моделей предлагается использовать уникальный номер, с указанием топологической связи с земельным участком, на котором расположен ОКС.

Китай. До 2018 года в Китае за регистрацию недвижимости отвечали различные ведомства, что приводило к дублированию работ в отношении одних и тех же объектов недвижимости. Также, существовавшая система регистрации недвижимости, основанная на 2D, не поддерживала моделирование различных географических объектов, и не давала возможности для описания и управления 3D-объектами [11].

С 2018 года все работы в отношении учета объектов недвижимости выполняются комитетом по земельным отношениям страны. Кроме этого, содержание законодательства о правах на объекты недвижимости было расширено до учета вертикального направления 3D-пространства снизу и сверху объекта недвижимости, что в итоге стало обеспечивать правовую основу для создания, регистрации и управления недвижимостью в формате 3D [14,15]. 
На сегодняшний день, наибольших успехов в данном вопросе достиг Шеньжень, благодаря наличию единого органа ответственного за кадастровый учет объектов недвижимости, планирования и развития городских территорий, геодезическое и картографическое и геологическое обеспечение, что позволяет избегать юридических препятствий при реализации концепции 3D-кадастра, затрагивающего каждого из указанных сфер [8]. Основными целями внедрения 3D-кадастра в Шеньжене является возможность учета и последующая продажа подземных пространств для размещения коммерческой недвижимости, а также описание объектов, находящихся на границе муниципалитетов.

Нидерланды. Нидерланды - первая страна, которая смогла внедрить 3D-кадастр. Изначально существовала система «многослойной собственности», т.е. устанавливались ограниченные вещные права на 2D-участок (сервитут, право долгосрочной аренды и право надстройки).

При регистрации прав на здание его контур представлял собой замкнутую линию, образуемую проекцией внешних границ ограждающих конструкций (стен) на горизонтальную плоскость, проходящую на уровне примыкания здания к поверхности земли [4].

Основная проблема возникала при передаче «многослойной собственности», когда вовлеченным сторонам (покупателю, продавцу и другим лицам, таким как ипотечный банк) необходимо реконструировать 3D-собственность по $2 \mathrm{D}$-кадастровой карте и документам, зарегистрированным в Земельной книге.

Для решения этой проблемы, были предложены усовершенствования, peaлизованные в два этапа.

В результате проведения первого этапа была разработана процедура принятия цифровой регистрации юридических актов в нидерландских земельных реестрах - таким образом, стала возможной регистрация 3D-объектов «многослойной собственности» в виде 3D PDF [7].

На втором этапе (проводится по настоящее время) был начат учет и регистрация 3D-участков (с расширение перечня сведений об объектах недвижимости). Особое место в регистрации 3D-объектов и прав занимают инженерные сети. Эти сети часто пересекают несколько земельных участков и таким образом имеют, кроме высоты или глубины, собственный трехмерный характер [13].

С 2007 г. в Нидерландах регистрация прав на все типы кабелей и трубопроводов стала обязательной. При этом, каждому объекту присваивается кадастровый номер. Контуры сетей могут включаться в топографический набор данных, который не является частью кадастровой карты. Таким объектам присваивают коды видимости. Если код видимости равен двум, то кабель или трубопровод невидим сверху.

Объектом для первой реальной 3D-регистрации стал проект комбинированной структуры мэрии и подземного железнодорожного вокзала в г. Делфт, показан на рис. 3. 

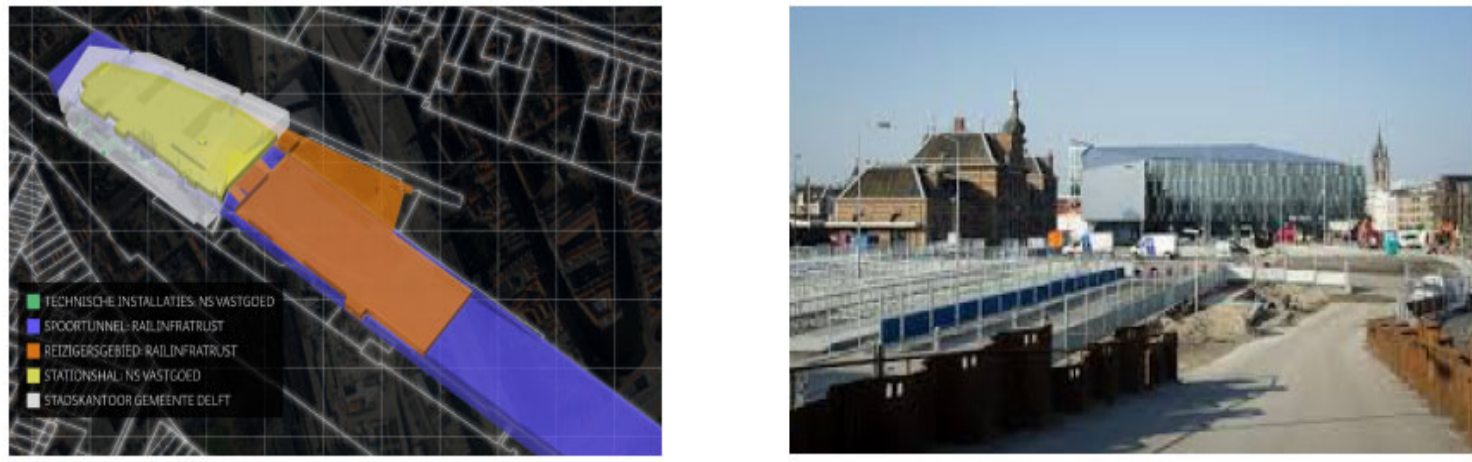

Рис. 3. Строительный комплекс станции Делфт

На сегодняшний день, в базе данных кадастра Нидерландов относительно объектов недвижимости, с учетом 3D-моделей, можно выделить следующие основные сведения:

- топологическая связь объекта с 2D участком;

- 3D-модель;

- 2D-сечение с дополнительной информацией;

- описание местоположения, а также привязка к земельному участку;

- координаты характерных точек и высоты.

Дальнейшим направлением развития системы 3D-кадастра Нидерландов является исключение пересечений и пустот между смежными 3D-моделями [13].

Исходя из результатов аналитического обзора были сделаны выводы о возможности использования приведенных решений в кадастре России:

1. Основным объектом кадастрового учета в 3D-кадастре является земельный участок и пространство над и под ним. В то же время, в России существует семь видов объектов недвижимости, из которых земельный участок - это 2Dмодель. Таким образом, на наш взгляд, целесообразно учитывать объекты капитального строительства, расположенные на земельном участке как часть 3D-пространства данного земельного участка;

2. Главной проблемой для внедрения 3D- кадастра является юридический аспект при регистрации и учете $3 \mathrm{D}$-моделей. Исходя из этого, многие страны пытаются ввести комплексные программы развития, включающие большое количество законов и нормативно-правовых актов. В России принята дорожная карта, предусматривающая переход на 3D-кадастр, однако на данный момент, существует только определение и содержание 3D-модели. Следовательно, необходимо проведение повторного пилотного проекта по внедрению 3D-кадастра на территории РФ и доработка карты, например, с учетом положительного опыта Нидерландов;

3. 3D-модель в зарубежных странах является совокупностью пересечения ограничивающих поверхностей. Данная методика показала свою эффективность и может быть реализована в кадастре РФ; 
4. В проанализированных странах отмечена слабая проработка вопроса учета подземных коммуникаций. Однако в Нидерландах существует возможность регистрации прав на любые типы кабелей и трубопроводов. В России часть инженерных коммуникаций отображается на топографических планах, в кадастре данные отсутствуют, таким образом, можно использовать положительный опыт Нидерландов.

Следовательно, можно сделать вывод, что для успешного внедрения 3D-кадастра необходимо принять ряд нормативно-правовых актов, утвердить методику формирования 3D-моделей, а также провести обучение необходимых ведомств. За основу рекомендуется взять решения, используемые в 3D-кадастре Нидерландов.

\section{БИБЛИОГРАФИЧЕСКИЙ СПИСОК}

1. Земельный участок как 3D объект или к вопросу о создании в РФ системы 3D кадастра недвижимости [Электронный ресурс] - Режим доступа: http://conf. omua.ru/content/ zemelnyyuchastok-kak-3d-obekt-ili-k-voprosu-o-sozdanii-v-rf-sistemy-3d-kadastra.

2. Лисицкий Д. В., Чернов А. В. Теоретические основы трехмерного кадастра объектов недвижимости // Вестник СГУГиТ. - 2018. - Т. 23, № 2. - С. 153-170.

3. Малыгина, О. И. Трехмерный кадастр - основа развития современного мегаполиса // Интерэкспо ГЕО-Сибирь-2012. VIII Междунар. науч. конгр. : Междунар. науч. конф. «Экономическое развитие Сибири и Дальнего Востока. Экономика природопользования, землеустройство, лесоустройство, управление недвижимостью» : сб. материалов в 4 т. (Новосибирск, 10-20 апреля 2012 г.). - Новосибирск : СГГА, 2012. Т. 1. - С. 129-133.

4. Опыт и перспективы применения $3 \mathrm{~d}$ кадастра при управлении градостроительным развитием подземного пространства [Электронный ресурс] - Режим доступа: https://cyberleninka.ru/article/n/opyt-i-perspektivy-primeneniya-3d-kadastra-pri-upravlenii-gradost roitelnym-razvitiem-podzemnogo-prostranstva.

5. Перспективы внедрения трехмерного кадастра в России [Электронный ресурс] - Peжим доступа: https://ntk.kubstu.ru/file/2003.

6. Перспективы создания 3D кадастра в России [Электронный ресурс] - Режим доступа: http://www.jena.ru/publish/62.html.

7. Чернов А. В., Окунева М. И. Основные этапы становления и развития 3D кадастра в странах-членах FIG // Интерэкспо ГЕО-Сибирь. XIV Междунар. науч. конгр. : Междунар. науч.-технолог. конф. студентов и молодых ученых «Молодежь. Наука. Технологии» : сб. материалов в 2 т. (Новосибирск, 23-27 апреля 2018 г.). - Новосибирск : СГУГиТ, 2018. Т. 1. C. $35-43$.

8. Шумаева К.В., Хлевная А.В., Мисюгина Е.Н. Зарубежный опыт применения 3D-кадастра недвижимости. В сборнике: ЛУЧШАЯ НАУЧНАЯ СТАТЬЯ 2016 сборник статей победителей $\mathrm{V}$ международного научно - практического конкурса. 2017. С. 389-394.

9. Andrée M. Virtual 3D Models as a Basis for Property Formation. [Электронный pecypc] / M. Andrée, S. Seipel, G. Milutinovic // FIG Working Week 2016 Recovery from Disaster Christchurch, New Zealand, 2016. Режим доступа: http://www.gdmc.nl/3DCadastres/literature/3Dcad_2016_04.pdf.

10. Jantine Esther Stoter. 3D Cadastre (2004) // перевод с англ. Виниченко Е.В. [Электронный pecypc] - Режим доступа: http://masters.donntu.org/2010/igg/vinichenko/lib rary/translate3.htm.

11. Kitsakis D. Possibilities of Integrating Public Law Restrictions to 3D Cadastres. [Электронный ресурс] / D.Kitsakis, E. Dimopoulou // FIG 3D Cadastre Workshop 2016, Athens, 
Greece. Режим доступа: http://www.gdmc.nl/3DCadastres/literature/3Dcad_2016_12.pdf Загл. с экрана.

12. Pouliot J. 3D Cadastre: With or Without Subsurface Utility Network [Электронный реcypc] / J. Pouliot, P. Girard. // FIG 3D Cadastre Workshop 2016, Athens, Greece. Режим доступа: http://www.gdmc.nl/3DCadastres/literature/3Dcad_2016_13.pdf - Загл. с экрана.

13. Pouliot J. Subsurface Utility Network Registration and the Publication of Real Rights: Pending for a Full 3D Cadastre. [Электронный pecypc] / J. Pouliot, P. Girard // FIG Working Week 2016 Recovery from Disaster Christchurch, New Zealand, 2016. Режим доступа: http://www.gdmc.nl/3DCadastres/literature/3Dcad_2016_01.pdf - Загл. с экрана.

14. Zhang J. The Application Model Of 3D Cadastre In Practical Registration For Real Estate In China [Электронный ресурс] / J Zhang . // FIG 3D Cadastre Workshop 2016, Athens, Greece. Режим доступа: http://www.gdmc.nl/3DCadastres/literature/3Dcad_2016_23.pdf Загл. с экрана.

15. Ying S, Guo R, Li L. An Uniform Real-Estate Registration Model For China [Электронный ресурс] / J Zhang . // FIG 3D Cadastre Workshop 2016, Athens, Greece. Режим доступа: http://www.gdmc.nl/3DCadastres/literature/3Dcad_2016_23.pdf - Загл. с экрана.

(C) А. И. Иванова, А. В. Чернов, 2021 